\title{
Post-hepatectomy tolvaptan-induced hypernatremia in a hepatocellular carcinoma patient with cirrhosis: a case report
}

\author{
Hiroya lida*, Hiromitsu Maehira, Haruki Mori, Tsuyoshi Maekawa and Masaji Tani
}

\begin{abstract}
Background: Tolvaptan is used in Japan to reduce fluid retention caused by cirrhosis. However, hypernatremia is one of the most important side effects. This report is the first case report of a patient who developed hypernatremia after tolvaptan administration in the early stages following hepatectomy.

Case presentation: A female patient in her $60 \mathrm{~s}$, who was admitted to the psychiatric department of a different hospital for bipolar disorder, developed hepatocellular carcinoma with cirrhosis. She was transferred to our hospital, and hepatectomy was performed in October 2019, after which pleural effusion and severe edema due to fluid retention were evident. Thus, the patient was started on tolvaptan $(7.5 \mathrm{mg} /$ day) from postoperative day (POD) 1. The patient began to experience disturbance of consciousness after POD 4. On the fifth day, the serum sodium ( $\mathrm{Na}$ ) level increased to $174 \mathrm{mEq} / \mathrm{L}$, and hypernatremia was diagnosed. The Na level gradually improved with fluid infusion therapy, dropping to preoperative levels on the ninth day; her consciousness also gradually improved.

Conclusions: Tolvaptan administration must be performed under strictly controlled conditions, followed by careful observation during the early postoperative period, when the patient's physical status is unstable.
\end{abstract}

Keywords: Hypernatremia, Tolvaptan, Hepatectomy, Hepatocellular carcinoma, Cirrhosis

\section{Background}

Tolvaptan is a drug that selectively controls water reabsorption in the kidney. It is an antagonist of the vasopressin-2 receptor (a protein expressed in the basolateral membrane of the principal cells of the collecting duct) and acts by inhibiting the aquaporin-2-mediated water transport. Unlike other types of diuretic agents, it selectively enhances water excretion and reduces electrolyte loss in the urine. Tolvaptan is used in Japan to control the progression of autosomal dominant polycystic kidney disease and to minimize fluid retention caused by heart failure, in situations where other diuretic agents are not successful [1-4]. This superiority in terms of

\footnotetext{
*Correspondence: hiroya@belle.shiga-med.ac.jp

Department of Surgery, Shiga University of Medical Science, Seta Tsukiniwa-Cho, Otsu, Shiga 520-2192, Japan
}

clinical efficacy has prompted its use as an agent to reduce fluid retention caused by cirrhosis $[5,6]$. Nevertheless, tolvaptan has several side effects, such as renal insufficiency, thromboembolism, acute hepatic insufficiency, hepatic dysfunction, shock, anaphylaxis, hepatic encephalopathy, pancytopenia, and hypernatremia. Here, we report a case of hepatocellular carcinoma (HCC) with cirrhosis, in which we administered tolvaptan after hepatectomy, ultimately leading in hypernatremia.

\section{Case presentation}

The patient was a female in her 60s, hospitalized in the psychiatric department of a different medical institute for bipolar disorder. In April 2018, we performed a laparoscopic partial resection of segment four (S4) of the liver in our hospital, as a local treatment for HCC.

\section{Springer Open}

(c) The Author(s). 2020 Open Access This article is licensed under a Creative Commons Attribution 4.0 International License, which permits use, sharing, adaptation, distribution and reproduction in any medium or format, as long as you give appropriate credit to the original author(s) and the source, provide a link to the Creative Commons licence, and indicate if changes were made. The images or other third party material in this article are included in the article's Creative Commons licence, unless indicated otherwise in a credit line to the material. If material is not included in the article's Creative Commons licence and your intended use is not permitted by statutory regulation or exceeds the permitted use, you will need to obtain permission directly from the copyright holder. To view a copy of this licence, visit http://creativecommons.org/licenses/by/4.0/. 
Disease recurrence was identified in September 2019, during follow-up observation, and the patient was readmitted to our hospital for surgical treatment. Her medical history indicated primary biliary cirrhosis, ovarian cystoma, bipolar disorder, and cholecystolithiasis (asymptomatic). She did not have any allergies, never smoked, and only consumed alcohol occasionally. Upon admission, her body weight and body mass index were $53.0 \mathrm{~kg}$ and $27.85 \mathrm{~kg} / \mathrm{m}^{2}$, respectively.

Contrast-enhanced computed tomography $(\mathrm{CT})$ of the abdomen showed a tumor at S4 with well enhancement in arterial phase and with washout in portal phase, $27 \times$ $18 \mathrm{~mm}$ in size. We also confirmed the presence of splenomegaly and splenorenal shunt but did not observe any gastric/esophageal varices or distant metastasis in the lungs or bones. In a gadolinium ethoxybenzyl diethylenetriamine pentaacetic acid-enhanced magnetic resonance imaging (MRI), we confirmed a tumor in the same region (S4), which showed high intensity in the arterial phase and low intensity in the hepatobiliary phase, adjacent to the S4 Glisson's capsule and the hilar plate.

Preoperative blood test results revealed a low platelet count $\left(103 \times 10^{3} / \mu \mathrm{L}\right)$, hypoalbuminemia $(3.0 \mathrm{~g} / \mathrm{dL})$, renal dysfunction $\left(55 \mathrm{~mL} / \mathrm{min} / 1.73 \mathrm{~m}^{2}\right.$ of estimated glomerular filtration rate), and an increased $\mathrm{Na}$ level $(151 \mathrm{mEq} /$ L) (Table 1).

The indocyanine green 15 min retention test value was $49.2 \%$, with a Child-Pugh score of 7 (class B). Preoperative chest radiography showed a $45.3 \%$ cardiothoracic ratio (CTR) with no evidence of pleural effusion.

We performed an open S4 sectionectomy in October 2019 to resect the tumor. The duration of the operation was $248 \mathrm{~min}$, and the blood loss was $595 \mathrm{~mL}$. The intraoperative infusion volume was $2110 \mathrm{~mL}$, and we administered $480 \mathrm{~mL}$ of fresh frozen plasma together with 10 units of platelet concentrates. The intraoperative urine volume was $680 \mathrm{~mL}$.

On postoperative day (POD) 1, the patient's level of consciousness was normal, and other vital signs were stable. Her weight increased from $53 \mathrm{~kg}$ (before the surgery) to $56.7 \mathrm{~kg}$, and whole-body edema, as well as right pleural effusion in the chest X-ray image were evident (Fig. 1). Despite an oxygen flow of $3 \mathrm{~L} / \mathrm{min}$, her

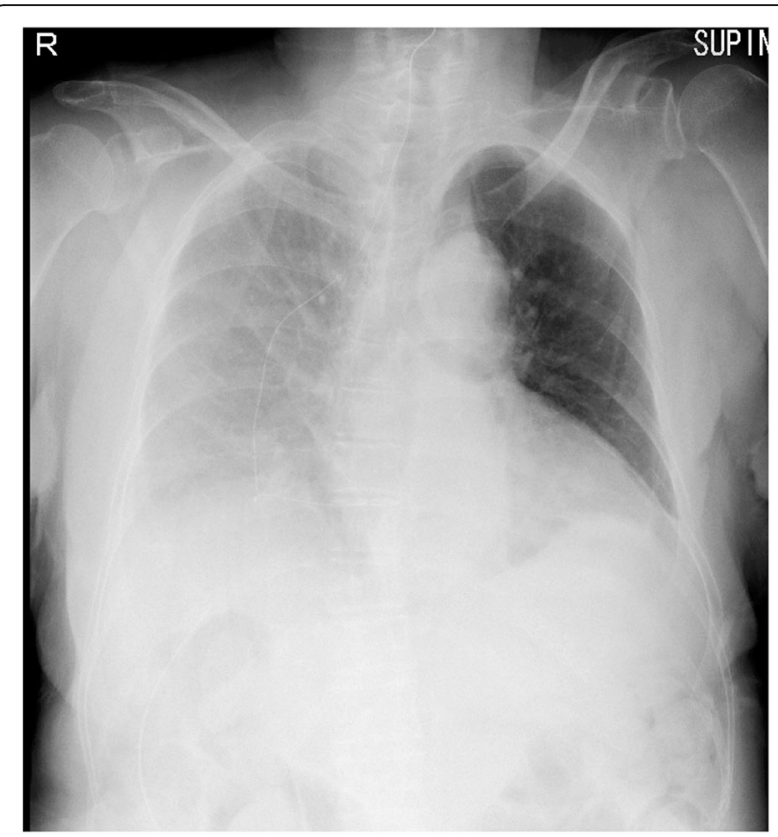

Fig. 1 Chest $X$-ray findings on POD 1. We confirmed a right pleural effusion in the chest X-ray image. The CTR showed increased to $66.7 \%$

peripheral oxygen saturation $\left(\mathrm{SpO}_{2}\right)$ level dropped to 92\%. The CTR was significantly increased (66.7\%) when compared to preoperative levels. We determined that this was due to the postoperative pleural effusion, and thus the patient was started on oral administration of tolvaptan and spironolactone at 7.5 and $25 \mathrm{mg} /$ day, respectively. The Na level was unchanged when compared with preoperative levels $(151 \mathrm{mEq} / \mathrm{L})$.

On POD 2, the patient's body temperature was $39{ }^{\circ} \mathrm{C}$ and she suffered from dyspnea and general fatigue. Since she showed delirium symptoms, anemia progression, decreased platelet count, increased inflammation, and hepatic transaminase levels, we performed a contrastenhanced CT. Although the abdominal CT showed normal postoperative changes, the chest $\mathrm{CT}$ allowed us to confirm a right pleural effusion and bilateral pneumonia (Fig. 2). We then fasted the patient and started the administration of antibacterial agents (tazobactam

Table 1 Preoperative laboratory findings

\begin{tabular}{|c|c|c|c|}
\hline Hemoglobin & $11.6 \mathrm{~g} / \mathrm{dL}$ & Total bilirubin & $1.1 \mathrm{mg} / \mathrm{dL}$ \\
\hline White blood count & $2.8 \times 10^{3} / \mu \mathrm{L}$ & $\mathrm{Na}$ & $151 \mathrm{mEq} / \mathrm{L}$ \\
\hline Platelet count & $103 \times 10^{3} / \mu \mathrm{L}$ & $\mathrm{Cl}$ & $118 \mathrm{mEq} / \mathrm{L}$ \\
\hline Prothrombin activity & $79 \%$ & K & $3.9 \mathrm{mEq} / \mathrm{L}$ \\
\hline Albumin & $3.0 \mathrm{~g} / \mathrm{dL}$ & Creatinine & $0.79 \mathrm{mg} / \mathrm{dl}$ \\
\hline AST & $31 \mathrm{IU} / \mathrm{L}$ & eGFR & $55 \mathrm{~mL} / \mathrm{min} / 1.73 \mathrm{~m}^{2}$ \\
\hline ALT & $19 \mathrm{IU} / \mathrm{L}$ & C-reactive protein & $0.27 \mathrm{mg} / \mathrm{dL}$ \\
\hline
\end{tabular}

ALT alanine aminotransferase, AST aspartate aminotransferase, eGFR estimated glomerular filtration rate 


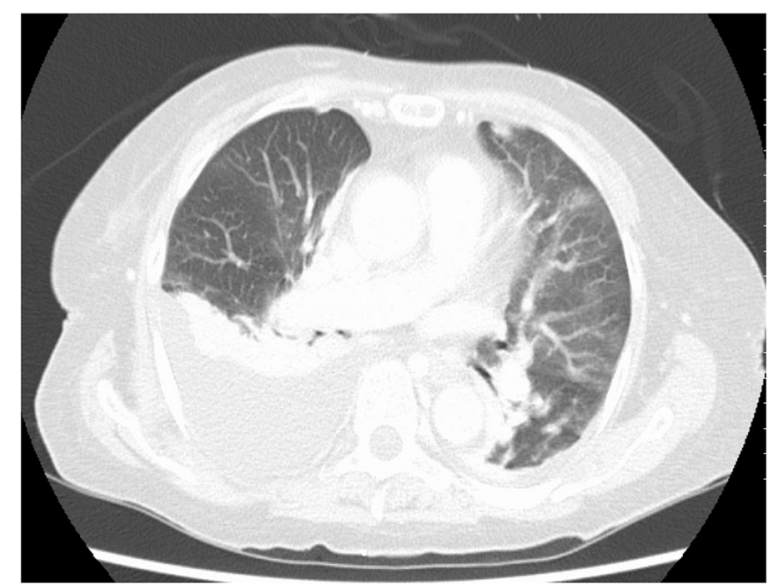

Fig. 2 Chest $C T$ findings on POD 2. Right pleural effusion and bilateral pneumonia were confirmed by a chest $C T$

piperacillin hydrate, $13.5 \mathrm{~g} /$ day). The Na level was normal on POD $2(143 \mathrm{mEq} / \mathrm{L})$.

On POD 3, her body temperature subsided to $37.2{ }^{\circ} \mathrm{C}$. She showed signs of clear consciousness, and the $\mathrm{SpO}_{2}$ level improved to $96 \%$ under an oxygen flow of $3 \mathrm{~L} / \mathrm{min}$. The daily urine volume was $4350 \mathrm{~mL}$. The CTR did not change significantly, but there was an improvement in the right pleural effusion (Fig. 3). The Na level increased to $161 \mathrm{mEq} / \mathrm{L}$.

On POD 4, at around 19:00, she showed disturbance of consciousness. We suspected that this condition was

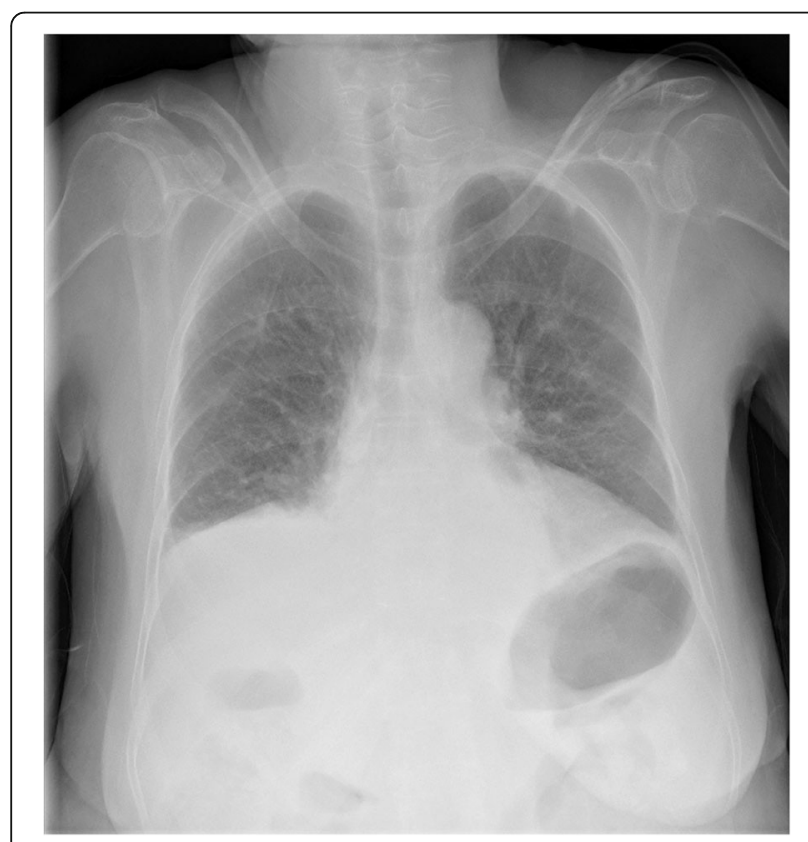

Fig. 3 Chest X-ray findings on POD 3. The right pleural effusion improved after tolvaptan administration, and no signs of pneumonia were found due to postoperative delirium, as confirmed by a psychiatrist.

The blood test on POD 5 showed an extremely high $\mathrm{Na}$ level $(174 \mathrm{mEq} / \mathrm{L})$, which led us to determine that the delirium was due to hypernatremia. We suspected that this could be a side effect of tolvaptan and immediately terminated its administration. The $\mathrm{Na}$ level gradually improved with fluid infusion therapy, dropping to preoperative levels on the ninth day; her consciousness also gradually improved (Fig. 4).

\section{Discussion}

Tolvaptan has been used in Europe and America since the late 2000s in patients with syndrome of inappropriate secretion of antidiuretic hormone, and several studies have reported its effectiveness in heart failure, and cirrhosis with hyponatremia [7, 8]. Tolvaptan is also recommended in the treatment guidelines for cirrhosisinduced ascites or edema in Europe and America [9]. In Japan, it was only introduced in 2014 for the treatment of cirrhosis-induced ascites or edema. Several studies have reported that tolvaptan administration is safe and can reduce body weight, ascitic fluid, and edema [10, 11]. It also reduces the effective dose of loop diuretics, thereby maintaining a normal renal function [12, 13]. Tolvaptan attenuates muscle loss in patients with cirrhosis, thereby improving their prognosis and quality of life [14-16]. However, there are several side effects that should be noted, with hypernatremia being one of the most important. It occurs due to its water diuresis effect, resulting in hemoconcentration that leads to hypernatremia in 1 to $5 \%$ of cases $[17,18]$. The severe cases are accompanied by disturbance of consciousness, which could lead to irreversible brain damage.

The patient developed hypernatremia following tolvaptan administration after hepatectomy for HCC. Tolvaptan was administered to deal with the exacerbation of physical status due to postoperative fluid retention. It is well known that the antidiuretic hormone vasopressin is released during the postoperative period and that those patients show symptoms of oliguria; tolvaptan has antagonist effects, which should suppress the fluid shifting to the third spaces. Therefore, tolvaptan administration was implemented to control postoperative fluid retention in hepatectomy patients with cirrhosis. The case discussed here differed from the norm, due to the relatively high preoperative $\mathrm{Na}$ levels, challenges in doctor-patient communication caused by the patient's mental disorder, and the fact that the treatment was performed during a fasting period initiated due to postoperative pneumonia.

Several studies have suggested that patients, who are elderly, have renal function disorders or have elevated blood $\mathrm{Na}$ levels tend to develop hypernatremia after tolvaptan administration, especially at a high dosage [18- 


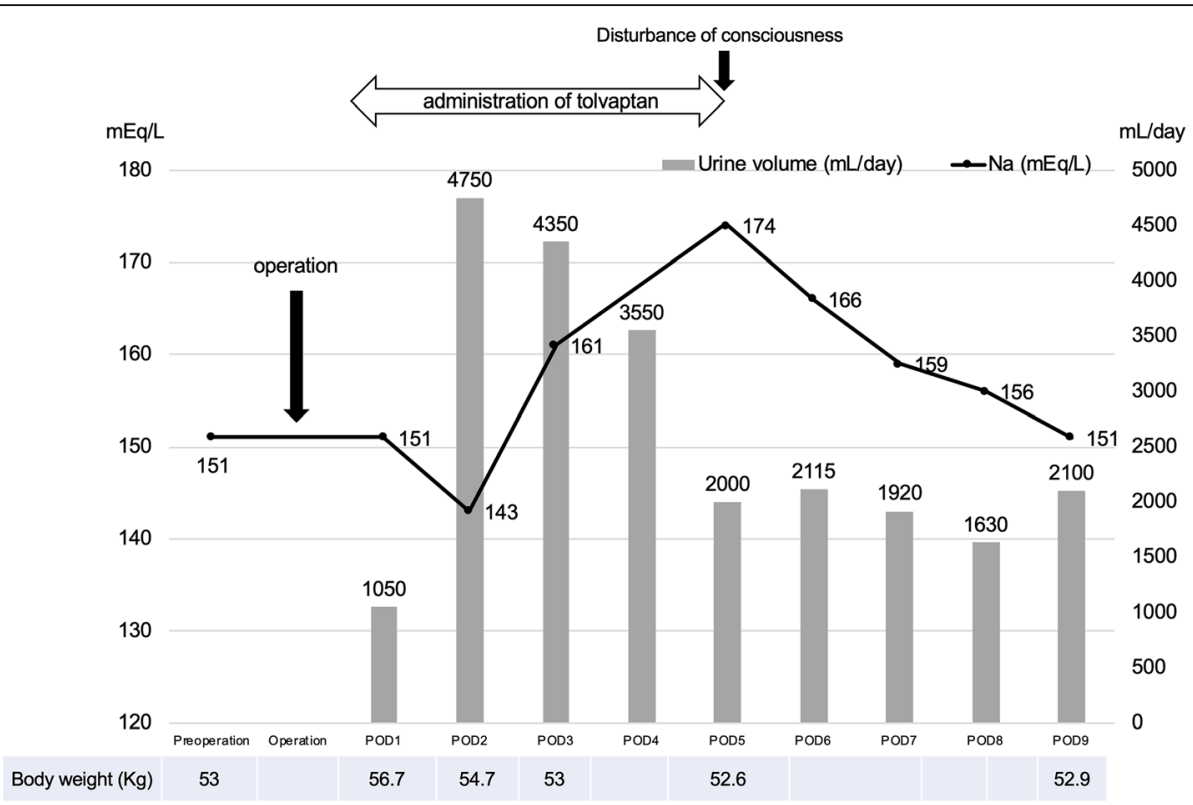

Fig. 4 Sequential changes in serum Na level, weight, and urine volume. Tolvaptan administration was started on POD 1; the Na level, which was $151 \mathrm{mEq} / \mathrm{L}$ before the surgery, rose to $174 \mathrm{mEq} / \mathrm{L}$ on POD 5. After terminating tolvaptan administration, the Na level gradually decreased and returned to the preoperative level by POD 9. The urine volume increased after tolvaptan administration to more than 4,000 mL/day. Body weight increased by $3.7 \mathrm{~kg}$ compared to the preoperative level; after tolvaptan administration, it returned to values similar to those observed before the operation

20]. A scoring system for predicting hypernatremia following tolvaptan administration has also been demonstrated (risk score $=0.125 \times$ serum sodium $(\mathrm{Na})+0.032$ $\times$ serum urea nitrogen $(\mathrm{BUN}) /$ serum creatinine $(\mathrm{Cr})-$ $0.436 \times$ serum potassium $(\mathrm{K})+0.014 \times$ age $)[18] . \mathrm{Pa}-$ tients with a score higher than 17.80 are considered to have a high risk of tolvaptan-induced hypernatremia. The subject of this study scored 18 and was thus in the high-risk group.

The patient had elevated preoperative blood $\mathrm{Na}$ level of $151 \mathrm{mEq} / \mathrm{L}$. As mentioned above, tolvaptan may not have been appropriate in the patient because high $\mathrm{Na}$ levels before administration of tolvaptan have been reported as a risk factor for tolvaptan-induced hypernatremia.

The cause of preoperative hypernatremia was unknown because the patient had no complications such as diabetes insipidus and no medications that elevate $\mathrm{Na}$ levels before surgery. However, the patient had a history of mental illness, and less complaints of excessive thirst could be the cause of hypernatremia. The hypernatremia following tolvaptan administration was due to a combination of various factors. In particular, it may have been induced by the surgical invasion on the condition of the patient whose $\mathrm{Na}$ level had elevated before the operation.

The final outcome of the patient was that her $\mathrm{Na}$ level and consciousness improved to preoperative condition, and she was discharged from our hospital. She has been followed up periodically after discharge and has no signs of recurrence of HCC and hypernatremia.
When administering tolvaptan to high-risk patients such as this case, it is necessary to start the administration at half the recommended dose $(3.75 \mathrm{mg} /$ day $)$ and check the $\mathrm{Na}$ level frequently.

\section{Conclusions}

This report is the first case report of a patient who developed hypernatremia after tolvaptan administration in the early stages following hepatectomy. This demonstrates that tolvaptan administration during the early postoperative period in which the patient's physical status is unpredictable should be carefully considered, and the patient's status during the following period must be closely monitored.

\section{Abbreviations \\ CT: Computed tomography; CTR: Cardiothoracic ratio; HCC: Hepatocellular carcinoma; MRI: Magnetic resonance imaging; POD: Postoperative day; S4: Segment four; $\mathrm{SpO}_{2}$ : Peripheral oxygen saturation}

\section{Acknowledgements}

None.

\section{Authors' contributions}

All authors contributed to the report conception. Treatments for the case were performed by $\mathrm{H}$. lida, H. Maehira, H. Mori, and T. Maekawa. The first draft of the manuscript was written by $\mathrm{H}$. lida and $\mathrm{M}$. Tani, and all authors commented on previous versions of the manuscript. All authors read and approved the final manuscript.

Funding

No funding was received. 


\section{Ethics approval and consent to participate}

All procedures followed were in accordance with the ethical standards laid down in the 1964 Declaration of Helsinki and its subsequent amendments,

\section{Consent for publication}

Written informed consent was obtained from the patients to publish their cases.

\section{Competing interests}

The authors report no proprietary or commercial interest in any of the products mentioned or the concepts discussed in this article.

Received: 11 February 2020 Accepted: 19 March 2020

Published online: 30 March 2020

\section{References}

1. Gheorghiade M, Niazi I, Ouyang J, Czerwiec F, Kambayashi Jl, Zampino M, et al. Vasopressin V2-receptor blockade with tolvaptan in patients with chronic heart failure: results from a double-blind, randomized trial. Circulation. 2003;107(21):2690-6.

2. Gheorghiade M, Konstam MA, Burnett JC Jr, Grinfeld L, Maggioni AP, Swedberg $K$, et al. Short-term clinical effects of tolvaptan, an oral vasopressin antagonist, in patients hospitalized for heart failure: the EVEREST clinical status trials. JAMA. 2007;297(12):1332-43.

3. Torres VE, Harris PC, Pirson Y. Autosomal dominant polycystic kidney disease. Lancet. 2007;369(9569):1287-301.

4. Chapman AB, Devuyst O, Eckardt KU, Gansevoort RT, Harris T, Horie S, et al. Autosomal-dominant polycystic kidney disease (ADPKD): executive summary from a Kidney Disease: Improving Global Outcomes (KDIGO) Controversies Conference. Kidney Int. 2015;88(1):17-27.

5. Okita K, Kawazoe S, Hasebe C, Kajimura K, Kaneko A, Okada M, et al. Dosefinding trial of tolvaptan in liver cirrhosis patients with hepatic edema: a randomized, double-blind, placebo-controlled trial. Hepatol Res. 2014;44(1): 83-91.

6. Sakaida I, Kawazoe S, Kajimura K, Saito T, Okuse C, Takaguchi K, et al. Tolvaptan for improvement of hepatic edema: a phase 3, multicenter, randomized, double-blind, placebo-controlled trial. Hepatol Res. 2014;44(1): 73-82.

7. Ginès $P$, Guevara M. Hyponatremia in cirrhosis: pathogenesis, clinical significance, and management. Hepatology. 2008:48(3):1002-10

8. Runyon BA. Management of adult patients with ascites due to cirrhosis: an update. Hepatology. 2009;49(6):2087-107.

9. Ginès P, Angeli P, Lenz K, Møller S, Moore K, Moreau R, et al. EASL clinical practice guidelines on the management of ascites, spontaneous bacterial peritonitis, and hepatorenal syndrome in cirrhosis. J Hepatol. 2010;53(3): 397-417.

10. Sakaida I, Terai S, Kurosaki M, Yasuda M, Okada M, Bando K, et al. Effectiveness and safety of tolvaptan in liver cirrhosis patients with edema: interim results of post-marketing surveillance of tolvaptan in liver cirrhosis (START study). Hepatol Res. 2017;47(11):1137-46.

11. Uojima H, Hidaka H, Nakayama T, Sung JH, Ichita C, Tokoro S, et al. Efficacy of combination therapy with natriuretic and aquaretic drugs in cirrhotic ascites patients: a randomized study. World J Gastroenterol. 2017;23(45): 8062-72.

12. Iwamoto T, Maeda M, Saeki I, Hidaka I, Tajima K, Ishikawa T, et al. Analysis of tolvaptan non-responders and outcomes of tolvaptan treatment of ascites. $J$ Gastroenterol Hepatol. 2019;34(7):1231-5.

13. Uojima H, Hidaka H, Tanaka Y, Wada N, Kubota K, Nakazawa T, et al. Furosemide dose changes associated with furosemide/tolvaptan combination therapy in patients with cirrhosis. Dig Dis. 2019;38(1):38-45.

14. Hiramine $\mathrm{Y}$, Uto H, Mawatari S, Kanmura S, Imamura Y, Hiwaki T, et al. Effect of tolvaptan on the prognosis of patients with hepatic ascites. Hepatol Res. 2019:49(7):765-77.

15. Kida Y. Positive response to tolvaptan treatment would be a good prognostic factor for cirrhotic patients with ascites. Dig Dis. 2019;37(3):23946.

16. Namba M, Hiramatsu A, Aikata H, Kodama K, Uchikawa S, Ohya K, et al. Management of refractory ascites attenuates muscle mass reduction and improves survival in patients with decompensated cirrhosis. J Gastroenterol. 2019;55(2):217-26
17. Berl T, Quittnat-Pelletier F, Verbalis JG, Schrier RW, Bichet DG, Ouyang J, et al. Oral tolvaptan is safe and effective in chronic hyponatremia. J Am Soc Nephrol. 2010;21(4):705-12.

18. Kinugawa K, Sato N, Inomata T, Yasuda M, Shibasaki Y, Shimakawa T. Novel risk score efficiently prevents tolvaptan-induced hypernatremic events in patients with heart failure. Circ J. 2018;82(5):1344-50.

19. Kinugawa K, Inomata T, Sato N, Yasuda M, Shimakawa T, Bando K, et al. Effectiveness and adverse events of tolvaptan in octogenarians with heart failure. Interim analyses of Samsca Post-Marketing Surveillance In Heart failurE (SMILE study). Int Heart J. 2015;56(2):137-43.

20. Hirai K, Shimomura T, Moriwaki H, Ishii H, Shimoshikiryo T, Tsuji D, et al. Risk factors for hypernatremia in patients with short- and long-term tolvaptan treatment. Eur J Clin Pharmacol. 2016;72(10):1177-83.

\section{Publisher's Note}

Springer Nature remains neutral with regard to jurisdictional claims in published maps and institutional affiliations.

\section{Submit your manuscript to a SpringerOpen ${ }^{\circ}$ journal and benefit from:}

- Convenient online submission

- Rigorous peer review

- Open access: articles freely available online

- High visibility within the field

- Retaining the copyright to your article

Submit your next manuscript at $\boldsymbol{\nabla}$ springeropen.com 